\title{
Health consequences of physical inactivity in women
}

\begin{abstract}
The health benefits of physical activity are numerous and include protection against chronic life style diseases like type 2 diabetes, obesity, hypertension, coronary artery disease, metabolic syndrome, prevention of certain cancers like cancer breast, endometrium, ovarian cancer and colorectal cancer. Physical activity improves mental and psychological health by reducing stress, anxiety and depression. It also improves bone health by preventing osteoporosis and reducing falls by increasing balance, co-ordination and flexibility in women. Physical activity is vital to the health of both women and men yet women are far less physically active compared to the male counterparts. Women face numerous barriers to being active and they include household caring and parenting demands, perception of safety and scarcity of time. The Governments should make strategies to increase the level of physical activity in females.
\end{abstract}

Keywords: physical activity, lifestyle disease, estrogen dependant cancer, women
Volume 4 Issue 4 - 2017

\author{
Rashmi Aggarwal \\ Department of Thyroid and Endocrine Research, Institute of \\ Nuclear Medicine and Allied Sciences, India \\ Correspondence: Rashmi Aggarwal, Department of Thyroid \\ and Endocrine Research, Institute of Nuclear Medicine and \\ Allied Sciences, Timarpur, Delhi, 54, India, Tel 0 I I-23905239, \\ 09818047498,Email drarashmi@yahoo.co.in
}

Received: February 02, 2017| Published: March 17, 2017

\section{Introduction}

Physical inactivity is the most important public health problem of the $21^{\text {st }}$ century. Regular physical activity not only reduces the risk of chronic life style diseases like hypertension, obesity, type 2 diabetes, coronary artery disease but it also reduces the risk of colon cancer and certain estrogen dependant malignancies such as breast and endometrial cancer. ${ }^{1}$ Physical activity also improves balance, flexibility, mental health and overall quality of life. Physical activity is especially important for the females. Numerous studies have shown that physical activity is an important factor in preventing osteopenia and osteoporosis. Depression and Alzheimers disease, both are much more common in women. ${ }^{2}$ Ravio et al., ${ }^{3}$ showed that regular physical activity may reduce the risk of dementia and Alzheimer's disease especially among genetically susceptible individuals. ${ }^{3}$ At the moment we have enough evidence supporting the fact that regular physical activity has important and widespread health benefits and we are all aware of this fact but then two things haunt me

i. The importance of physical activity is underappreciated in our clinical day to day practice. ${ }^{4}$

ii. Women world over are less active compared to their male counterparts.

A CDC report indicated that only $19 \%$ of physicians counseled their patients about exercise. Results of a multicenter trial suggest that clinicians can easily learn to add 3 to 4 minutes of physical activity advice into routine office visits and that counseling can increase activity in sedentary patients. ${ }^{5}$ Few studies done in India comparing the level of physical activity in males and females show that in India females are more physically in active compared to males. The reasons for greater physical in activity in females in India include the fact that females play the role of care giver in most households and do find time and adequate oppurtunities in terms of gymnasiums or play ground in the vicinity of their homes. Working women have to bear the double burden of looking after the household chores as well as the office work. Females in India are also lowly paid as compared to the males. Indian council of medical research - India Diabetes (ICMRINDIAB) study is a large ongoing cross sectional, community based survey involving adults of both sexes aged 20years and above (Table 1). The study when completed will have sampled from 28 states of India, the National Capital Territory of Delhi and 2 union territories namely Chandigarh and Delhi. In view of the complexities of the study and the logistics involved, the study has been planned and undertaken in phases. Phase 1 of this study has studied a representative sample of three states and one union territory of India covering a population of 213 million and is the largest study of its kind from India. The authors of this landmark study found that there was a significant difference among males and females with respect to physical activity, with males being more active. This is in agreement with earlier studies, most of which have reported higher level of activity in males compared to females. ${ }^{8}$ I think policy makers world over must concentrate on developing programmes and policies to increase physical activity in a predominantly sedentary population especially women in all age groups. Physical activity in young girls helps them to develop better self esteem while physical activity in older women leads to better coordination, balance, flexibility and improved cognition and bone health. 
Table I Comparison of physical inactivity between males and females from India

\begin{tabular}{|c|c|c|c|}
\hline Authors & Regions studied & $\begin{array}{l}\text { Physical inactivity } \\
\text { in males }\end{array}$ & $\begin{array}{l}\text { Physical inactivity in } \\
\text { females }\end{array}$ \\
\hline Shah et al. ${ }^{6}$ & $\begin{array}{l}6 \text { regions( Delhi and Balladgarh in north, Chennai and Trivandrum in south, } \\
\text { Nagpur in west and Dibrugarh in east) }\end{array}$ & $12.60 \%$ & $18.90 \%$ \\
\hline Gupta et al. ${ }^{7}$ & 11 cities across India & $38.80 \%$ & $46.10 \%$ \\
\hline Anjana et al. ${ }^{8}$ & 3 states(Tamil Nadu, Maharashtra, Jharkand) 1 union territory (Chandigarh) & $45.70 \%$ & $63.00 \%$ \\
\hline
\end{tabular}

\section{Physical inactivity and hypertension}

Aging is associated with an increase in stiffness of arteries leading to an increase in after load of left atria and resulting in systolic hypertension. Physical activity is the cornerstone of therapy for prevention, treatment and control of hypertension. Brennan et al., ${ }^{9}$ recognized that isolated hypertension was present mostly in elderly women. They studied 109 elderly women, of whom $63.3 \%$ were hypertensive and they found that the mean systolic blood pressure was lower among those women who were moving 5 or more hours per day. ${ }^{9}$ The American College of Sports Medicine recommends at least 30 minutes of moderate intensity physical activity for hypertensive patients.

\section{Physical inactivity and type 2 diabetes mellitus}

The two major risk factors for development of type 2 diabetes are abdominal obesity and physical inactivity. Hu et al., ${ }^{10}$ followed up 84941 female nurses for 16years. At the baseline this cohort was free from coronary artery disease, diabetes mellitus and cancer. The authors concluded that $91 \%$ of 3300 new cases of type 2 diabetes were due to physical inactivity. ${ }^{10}$

\section{Physical inactivity and ovarian cancer}

There is significant inverse association between vigorous physical activity and ovarian cancer. This inverse association was also seen in Copenhagen City Heart study. ${ }^{11}$ Increase physical activity lowers the risk of ovarian cancer by decreasing sex hormones and possibly by reducing the frequency of ovulation. A Chinese study concluded that the risk of ovarian cancer declined with increase in duration of strenuous activity. ${ }^{12}$

\section{Physical inactivity and breast cancer}

Breast cancer is the most common malignancy in females and is the second leading cause of cancer death in females. Numerous studies have shown that an increase in the level of physical activity reduces the risk of breast cancer. The possible mechanisms by which enhanced physical activity reduces breast cancer risk are multiple and include reduced adiposity, insulin resistance, sex hormone levels and inflammatory markers. ${ }^{13}$ Studies indicate that physical activity after a diagnosis of breast cancer may be beneficial in improving quality of life. ${ }^{14}$

\section{Physical inactivity and cardiovascular disease}

Cardiovascular disease (CVD) is the leading cause of death for both men and women and accounts for more hospitalizations than any other illness. While traditionally perceived as an affliction of middle-aged males, CVD is responsible for a greater proportion of total mortality among women $(39 \%)$ than men $(36 \%)^{15}$ Gender differences in the clinical presentation as well as outcome of Cardiovascular disease are well recognised. Morbidity from myocardial infarction is greater for women than men and nearly $40 \%$ of all coronary events in women are fatal. ${ }^{16}$ The mechanisms by which physical activity offers protection against CVD include its direct effects on cardiovascular system where it improves myocardial circulation and contractility of the myocardial muscles. Physical activity also reduces blood pressure, normalises the deranged lipid parameters, improves glycaemia control and insulin sensitivity. It also reduces anxiety and psychological stress.

\section{Other benefits of physical activity}

Physical activity in any form be it sports, house hold chores such as gardening, active transport or occupational activity, leads to positive effects on physical, mental and psychological health of both healthy females and those who are coping with any form of disease like coronary artery disease, osteoporosis, oestrogen dependent malignancies, type 2 diabetes and metabolic syndrome. Physical activity is also important for psychological well being of females especially those suffering from depression, anxiety, stress, post menopausal symptoms, fibromyalgia. Young girls suffering from eating disorders or low self esteem also benefit from regular physical activity. ${ }^{17}$ Women who participate in regular physical activity sleep more and experience a better quality of sleep than women who are sedentary. ${ }^{18}$

\section{Conclusion}

We are all aware of the fact that physical activity has multiple positive effects on women's health yet women's participation in physical activity remains low. Women have to face the double burden of house hold and child care leaving them with little time for participation in physical activity. Apart from scarcity of time due to parenting issues, the fear of victimization and crime is another barrier preventing women from active participation in physical activity. Therefore the government and non government organization should work on increasing the level of participation of women in physical activity. This can be achieved by increasing awareness among the women folk regarding the health benefits of physical activity. Health professionals should advice and discuss the advantages of physical activity with the patients. Efforts should be made to design environments where women feel safe within their communities. All these initiatives will help to improve the level of physical activity in women and thereby improve the overall health of women world over.

\section{Acknowledgements}

None. 


\section{Conflict of interest}

The author declares no conflict of interest.

\section{References}

1. Joseph AK. Physical inactivity: Associated disease and disorders. Annals of Clin and Lab Sci. 2012;42(3):320-337.

2. Scarmeas N, Luchsinger JA, Schupf N, et al. Physical activity, diet and risk of Alzheimer disease. JAMA. 2009;302(6):627-637.

3. Rovio S, Kåreholt I, Helkala EL, et al. Leisure time physical activity at midlife and risk of dementia and Alzheimer's disease. Lancet Neurol. 2005;4(11):690-691.

4. Centers for Disease Control and Prevention (CDC). Missed opportunities in preventive counseling for cardiovascular disease -United States, 1995. MMWR Morb Mortal Wkly Rep. 1998;47(5):91-95.

5. Albright CL, Cohen S, Gibbons L, Miller S, Marcus B, et al. (2000) Incorporating physical activity advice into primary care: physiciandelivered advice within the activity counseling trial. Am J Prev Med 18(3): 225-234.

6. Shah B. Development of sentinel health monitoring centre for surveillance of risk factors of non communicable diseases in India(April 2003 to March 2005): Collated results of 6 centres. Indian Council of Medical Research, Switzerland: WHO; 2005. p. 1-71.

7. Gupta R, Deedwania PC, Sharma K, et al. Association of educational, occupational and socioeconomic status with cardiovascular risk factors in Asian Indians: a cross sectional study. Plos one. 2012;7(8):e44098.

8. Anjana RM, Pradeepa R, Das AK, et al. Physical activity and inactivity patterns from the ICMR-INDIAB study (phase-1). Int J Behav Nutr Phys Act. 2014;11(1):26-37.
9. Brennan P, Pescatello LS, Bohannon RW, et al. Time spent moving is related to systolic bold pressure among older women. Prev Cardiol. 2005;8(3):160-164.

10. Hu FB, Manson JE, Stampfer MJ, et al. Diet, lifestyle and risk of type 2 diabetes mellitus in women. $N$ Engl J Med. 2001;344:1343-1350.

11. Pan SY, Ugnat AM, Mao Y. Physical activity and risk of ovarian cancer: a case control study in Canada. Int J Cancer. 2005;117(2):300-307.

12. Zhang M, Lee AH, Binns CW. Physical activity and epithelial ovarian cancer risk: a case control study in China. Int J Cancer. 2003;105(6):838843.

13. McTiernan A. Mechanisms linking physical activity with cancer. Nat Rev Cancer. 2008;8(3):205-211.

14. Holmes MD, Chen WY, Feskanich D, et al. Physical activity and survival after breast cancer diagnosis. JAMA. 2005;293(20):2479-2486.

15. Wenger NK. Preventative coronary interventions for women. Med Sci Sports Exerc. 1996;28(1):3-6.

16. Judelson DR. Coronary heart disease in women: Risk factors and prevention. Journal of the American Medical Association. 1994;49:186197

17. Bailey R, Wellard I, Dismore H. Girls and physical activity: a systematic review. Educ Health. 2005;23:3-5.

18. de Castro Toledo Guimaraes LH, de Carvalho LB, Yanaguibashi G, et al. Physically active elderly women sleep more and better than sedentary women. Sleep Med. 2008;9(5):488-493. 